\title{
Correction: Suprapubic pedicled phalloplasty in transgender men: a multicentric retrospective cohort analysis
}

\section{Falcone Marco - Timpano Massimiliano - Oderda Marco - Cocci Andrea - Morelli Girolamo - Preto Mirko • Polito Chiara • Russo Giorgio Ivan • Gideon Blecher • Gontero Paolo}

Published online: 2 April 2020

(c) The Author(s), under exclusive licence to Springer Nature Limited 2020

\section{Correction to: International Journal of Impotence Research https://doi.org/10.1038/s41443-020-0238-4}

The original version of this article contained errors in the names and surnames of the authors, which were incorrectly given as:

Marco, Falcone

Massimiliano, Timpano

Marco, Oderda

Andrea, Cocci

Girolamo, Morelli

Mirko, Preto

Chiara, Polito

Ivan, Russo Giorgio

Blecher, Gideon
Paolo, Gontero.

Whereas they should have been given as:

Falcone, Marco

Timpano, Massimiliano

Oderda, Marco

Cocci, Andrea

Morelli, Girolamo

Preto, Mirko

Polito, Chiara

Russo, Giorgio Ivan

Blecher, Gideon

Gontero, Paolo.

This has now been corrected in both the PDF and HTML versions of the article. 